\title{
Total Bilirubin Level Finding
}

National Cancer Institute

\section{Source}

National Cancer Institute. Total Bilirubin Level Finding. NCI Thesaurus. Code C157422.

A finding that indicates the amount of total bilirubin in a sample. 